\title{
Next-Generation Cryo-Electric Hydrogen-Powered Aviation
}

This paper was downloaded from TechRxiv (https://www.techrxiv.org).

\section{LICENSE}

CC BY 4.0

SUBMISSION DATE / POSTED DATE

$17-12-2021 / 28-12-2021$

CITATION

Nøland, Jonas Kristiansen; Hartmann, Christian; Mellerud, Runar (2021): Next-Generation Cryo-Electric Hydrogen-Powered Aviation. TechRxiv. Preprint. https://doi.org/10.36227/techrxiv.17264234.v1

$\mathrm{DOI}$

10.36227/techrxiv.17264234.v1 


\section{Next-Generation Cryo-Electric Hydrogen-Powered Aviation}

A Disruptive Superconducting Propulsion System Cooled by Onboard Cryogenic Fuels

\section{By Jonas Kristiansen Nøland, Christian Hartmann, and Runar Mellerud}

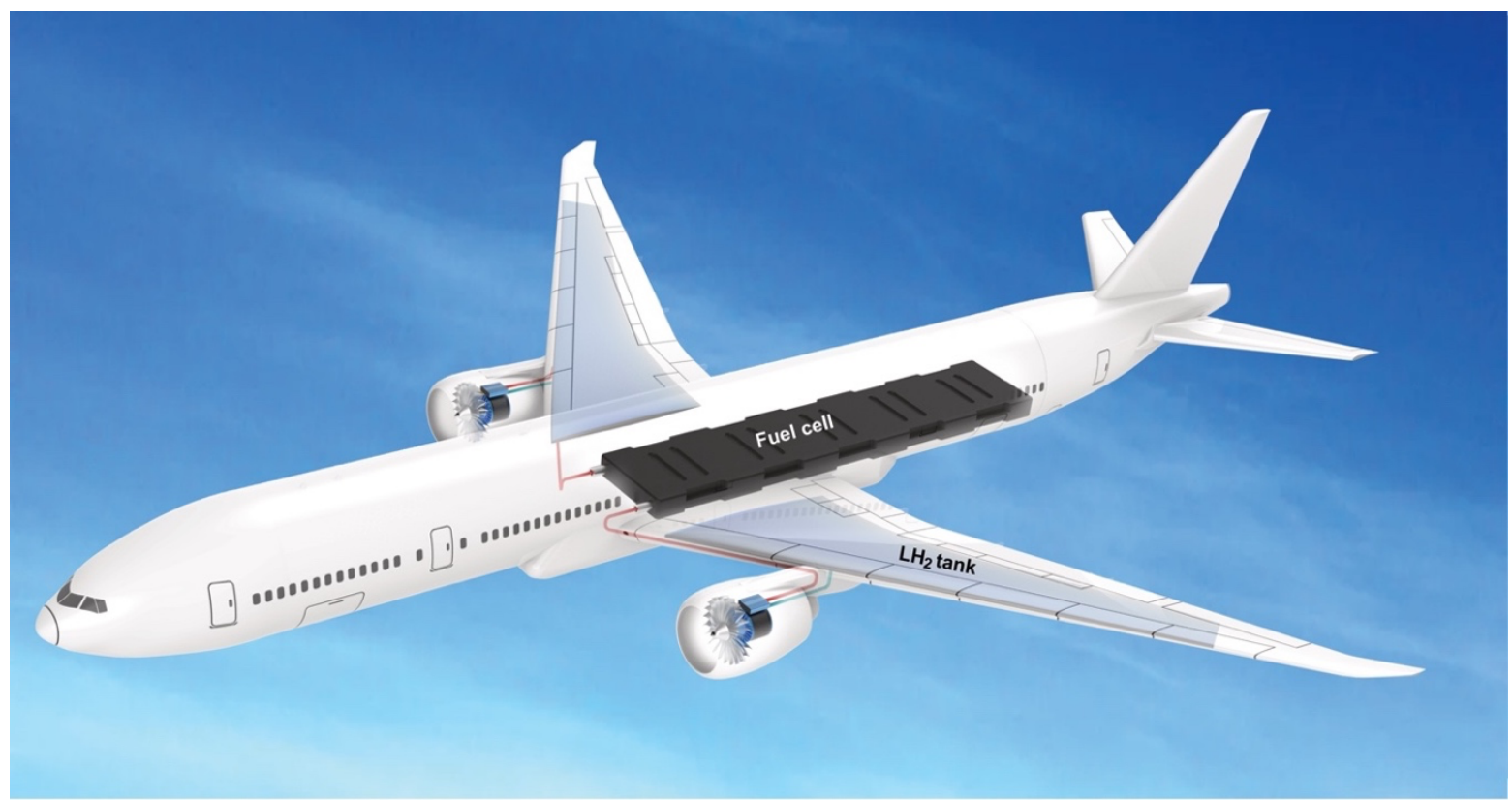

Figure 1 Proposed wildcard cryo-electric airplane, installing $\mathrm{LH}_{2}$ tanks in the wings and fuel cells onboard the fuselage.

\section{Abstract}

Hydrogen-powered airplanes have recently attracted a revitalized push in the aviation sector to combat $\mathrm{CO}_{2}$ emissions. However, to also reduce, or even eliminate, non- $\mathrm{CO}_{2}$ emissions and contrails, the combination of hydrogen with all-electric solutions is undoubtedly the best option to move toward the ambitious goal of climate-neutral aviation. Another important design choice is to store hydrogen cryogenically in its liquid form $\left(\mathrm{LH}_{2}\right)$ to reduce space occupation compared to storage as compressed gas. However, the $\mathrm{LH}_{2}$ fuels cannot be utilized directly in fuel cells. It needs to be brought from liquid to a gas at about $350 \mathrm{~K}$, where large amounts of heat must be added. Thus, a synergy can be made from this otherwise wasted cryogenic refrigeration power where superconducting machines (SCMs) and cold power electronics (CPE) are low-hanging fruits that could lead to radical space and weight reductions onboard the aircraft. These opportunities can be realized without having to pay the price, nor the volume occupation and mass needed for the cooling ability usually needed to achieve these extraordinary performances. In fact, this ground-breaking synergy makes cryogenic energy conversion relevant in a whole new way for aviation. The SCMs' more than five times higher power densities than their 
conventional counterparts are exceptionally significant. This article introduces the recently proposed cryo-electric drivetrain initiatives and explores the opportunities of using direct hydrogen cooling as a potential heating solution to enhance the overall performance and scalability of zero-emission propulsion systems in future regional aircraft.

\section{Introduction}

Conventional aircraft rely on energy-dense fuels as well as strict weight and certification requirements. Until recently, it has been challenging to transform the aviation industry into a resilient and sustainable one, focusing primarily on energy-dilute and heavy batteries. However, a paradigm shift is now occurring, where aerospace industries and stakeholders consider lightweight hydrogen fuel as a renewable surrogate onboard the aircraft [1]. While gaseous hydrogen $\left(\mathrm{GH}_{2}\right)$ is already low in mass, it needs a lot of space to be stored. Compressed hydrogen (200-700 bar) is one alternative, but it is not the most spaceefficient solution. Liquid hydrogen $\left(\mathrm{LH}_{2}\right)$ at $20 \mathrm{~K}$ and 1 bar can further reduce the volume by 50 percent [2], which allows the airplane to hold significantly more fuel.

It is often assumed that $\mathrm{LH}_{2}$ must be stored in either spherical or cylindrical tanks. However, in traditional airframe designs, their bulkiness forces them into the fuselage, which reduces available space for passengers and luggage. The main argument for using such tanks is that they have low surface areas, yielding low boil-off rates of around 1.5 percent per day [3]. In aviation, the predictable fuel consumption pattern can use boil-off directly as fuel, as one only needs to store the $\mathrm{LH}_{2}$ for hours at a time. Hence, the higher boil-off rate of flatter tanks customized to fit inside the wings (see Figure 1) seems inconsequential compared to the advantage of their lower volume usage. However, the main challenge is that these tanks are not available today and have to be developed in the coming years.

The most efficient and climate-friendly solution for hydrogen-power aircraft is to go for fully electric propulsion, but overall, this solution is very mass-intensive. However, superconducting machines (SCMs) have lately been proposed in aviation to be at least five times power-dense than existing solutions (i.e., $25 \mathrm{~kW} / \mathrm{kg}$ and beyond), but it overlooks the SCMs' inherently energy- and weight-intensive cryogenic cooling needs. Contrary to this limitation, a new class of SCMs can be enabled using the $\mathrm{LH}_{2}$ fuel onboard the aircraft as a cryogenic cooling medium [4]. Also in gas form, hydrogen is a widely used coolant, especially at higher temperatures $[5,6]$. Moreover, hydrogen needs to hold at least $60^{\circ} \mathrm{C}$ when consumed in fuel cells, which means it has to be boiled and heated on its way from the tank. This need creates a synergy where there are new achievable breakthroughs in performance of utilizing the direct cooling capacity of hydrogen to enable:

$\checkmark$ SCMs cooled at temperatures between $20 \mathrm{~K}$ and $60 \mathrm{~K}$;

$\checkmark$ High-temperature superconducting (HTS) AC and DC cables chilled at $\sim 80 \mathrm{~K}$; and,

$\checkmark$ Cold power electronics (CPE) operating at $\sim 160 \mathrm{~K}$.

In order to utilize most of the high-value cryogenic properties of the hydrogen fuel, taking advantage of a wide enough temperature span, the components should be operated and designed for different temperature intervals, optimizing the overall system performance. By providing the coldest $\mathrm{H}_{2}$ for the 
SCMs first, their power density enhances significantly when heavy cryocoolers are avoided (see Figure 2 for simplified drawing).

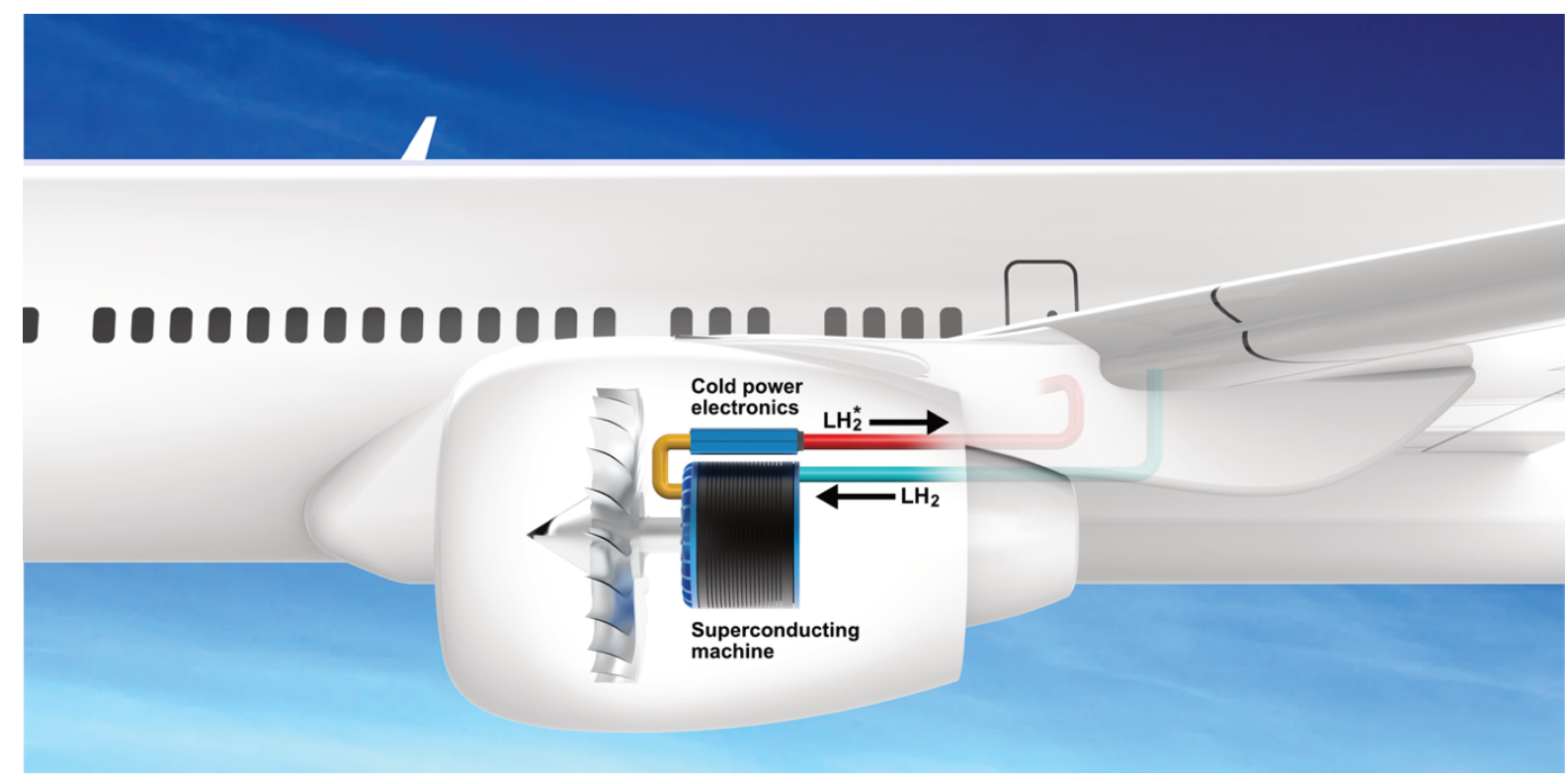

Figure 2 Hydrogen-cooled superconducting machine and cold power electronics inverter (outgoing $\mathrm{LH}_{2}{ }^{*}$ is no longer liquid).

It should be emphasized that conventional electrical technology is not even close to approaching these performances. By sophisticated lightweight construction techniques, the most power-dense permanent magnet machine achieves a power density of $5.2 \mathrm{~kW} / \mathrm{kg}$ (i.e., $260 \mathrm{~kW}, 2500 \mathrm{rpm}, 50 \mathrm{~kg}$ direct-driven motor demonstrated by Siemens in 2015). However, it is still too heavy to be used for multi-megawatt electric propulsion [7]. In fact, a turbo-electric retrofit for a 100-seater aircraft requires an electric machine powerto-weight (PTW) ratio of at least $16 \mathrm{~kW} / \mathrm{kg}$ [8], compatible with SCMs' $20 \mathrm{~kW} / \mathrm{kg}$ and beyond [9].

It is also worth noting that SCMs chilled by $\mathrm{LH}_{2}$ at $20 \mathrm{~K}$ can achieve higher power density than liquid nitrogen $\left(\mathrm{LN}_{2}\right)$ at $63 \mathrm{~K}$ due to the intrinsically higher current densities available at lower temperatures [10]. However, one must also consider the cooling penalty; A conventional cryocooler removes $1 \mathrm{~W}$ at $20 \mathrm{~K}$ at the expense of as much as $100 \mathrm{~W}$, considering the ideal Carnot cycle and an efficiency of the cooling machine of $15 \%$. In fact, the penalty of the weight and the power of the cryocooler is often overlooked in merely theoretical SCM performance evaluations, as they diminish their benefits. However, most serious researchers and industrial developers take mass and power penalties into account to be transparent about potential gains and drawbacks.

Even though SCMs with cryocoolers are hard to sell to stakeholders, using direct hydrogen cooling as a synergy to chill the SCM at $20 \mathrm{~K}$ could be much easier to justify. This is also the case of feeding hydrogen in gas form after the $\mathrm{LH}_{2}$ is fully boiled. The gaseous $\mathrm{H}_{2}$ could be used to keep the temperature of the superconductors below $30 \mathrm{~K}$. However, the current density of magnesium diboride $\left(\mathrm{MgB}_{2}\right)$ is quite limited at $30 \mathrm{~K}$, so keeping it below $25 \mathrm{~K}$ should be the ultimate goal. 
From the above considerations, a case can be made using cryogenically stored hydrogen fuel onboard the aircraft to actively cool components and enable previously unobtainable performance. The lightweight performance enabled by this transformative propulsion concept provides a pathway for widescale, true zero-emission hydrogen aircraft that are otherwise impossible to obtain, considering the low scalability of conventional electrical technologies and the high climate impact hydrogen combustion [1].

\section{Important Contributions to the Core Technologies}

The new focus on zero-emission aviation at scale demands $1 \mathrm{MW}$ to $5 \mathrm{MW}$ electric motors, which are needed for large propulsion systems (e.g., A320, A350). Herein, the machine's efficiency and power density are the key figures-of-merit, to pave the way to cleaner aviation in regional flights and beyond. Two important solutions for scalability is the introduction of SCMs and CPE, where recent works are covered in the following.

\section{Superconducting Machines (SCMs)}

Early SCMs were synchronous machines using superconducting dc field windings only. However, to push it further, the EU-funded project ASUMED was set up to develop and test the first aerospace-grade fully-superconducting motor [11], where the stator uses $\mathrm{LH}_{2}$ and the rotor gaseous helium (GHe). ASuMED aimed at a power density of $20 \mathrm{~kW} / \mathrm{kg}$ using a HTS stator solution [12], and was intended to be suitable for hybrid-electric distributed propulsion (HEDP) in future aviation.

The rotor utilized stacked superconductors that basically function as permanent magnets with high remanent flux density, and are therefore premised on the basis that the overall power density favors a high air-gap flux density that cannot be obtained by passive permanent magnets (PMs). Superconducting magnets can be more than 10 times stronger than conventional ones, but are continuously being pushed further, as shown by the recent world record of $17.9 \mathrm{~T}$ [13]. However, these magnets are not suited for electrical machines, where a maximum of $3 \mathrm{~T}$ is usually considered within the feasible range.

The main drawback of the ASUMED demonstrator is the fact that a high flux density from the rotor often breaks the saturation limit of the core [14], which in turn increases the weight of the machine. However, it provided the next step to make the AC windings in the stator superconducting as well. The main rationale for the ASUMED project was the fact that the option of a fully superconducting machine is far from a mature technology [15].

A more robust option is to solely focus on making the stator AC-windings superconducting instead, which is static and easier to cool for the cryogenic system. Moreover, recent studies on fully superconducting SCMs show that they are often optimized to be lightweight at air gap magnetic flux densities below $0.9 \mathrm{~T}$ [16]. As a result, a superconducting rotor might be more of a burden rather than an opportunity. For the rotor part, PMs can achieve a remanent magnetization of up to $1.3 \mathrm{~T}$, which appears to be sufficient in many cases. 
An alternative solution to set up the magnetic field from the rotor is to use PMs and arrange them in a Halbach array. Such a configuration avoids the need for magnetic iron parts in the rotor, which has the potential for further reductions in the active weight. PMs are also considered a reliable magnetic source to provide safe torque generation in general aviation systems, as they are not dependent on active components [17].

\section{Cold and Cryogenic Power Electronics (CPE)}

Cryogenic power electronics have earlier been proposed to increase the power density of energy conversion systems [18]. Silicon MOSFET switching devices have already shown efficiency improvements when running at cryogenic temperatures (77 K) [19], however, that is still not the case for Silicon Carbide (SiC) MOSFETs [20]. At switching frequencies of $140 \mathrm{kHz}$, a cryogenic 40-kW three-level NPC inverter showed 30 percent less losses than at room temperature [21]. Moreover, the operation of Gallium Nitride (GaN) power devices has been demonstrated over a temperature range from $400 \mathrm{~K}$ and down to $4.2 \mathrm{~K}$, allowing high operational flexibility [22]. GaN devices have also been shown to have an overload current capability of four times the rated capacity when cryogenically cooled [23]. Already at $213 \mathrm{~K}$, a single-phase 1-kW GaN inverter at $60 \mathrm{~Hz}$ load frequency exhibited a 16 percent reduction in losses compared to room temperatures [24]. A myriad of similar observations also makes a case for the recent trend of "cold" power electronics (CPE), proposing an operating temperature of about $160 \mathrm{~K}$.

As the operating temperature drops, power electronic devices can be utilized with minimal resistive losses, ensuring excess heat load into the wider system is kept to a minimum. It also increases the permissible current loading, leading to higher power to weight ratios (e.g., 36kW/kg at continuous operating levels). Besides a direct reduction in volume and weight, the efficiency increase of the CPE leads to lower requirements for heat removal. In the case of hydrogen-electric aircraft, it translates to using $\mathrm{H}_{2}$ for other high-value cooling purposes as well.

\section{Combining Cold Power Electronics and Superconducting Machines}

The recently proposed ASCEND project introduces a propulsion system demonstrator specified in Table 2 , where the system layout is depicted in Figure 3. The overall targets for each component and the desired figure-of-merit for the end product in provided is Table 1. They show that taking all electrical components into account adds significant mass and heat loss penalties to the overall system configuration. As a result, more realistic values for the systems' power density and overall efficiency are identified. These additional inefficiencies occurring throughout the system would add additional cooling needs and heat exchange mass if these losses could not be handled by synergizing the hydrogen fuel distribution system of $\mathrm{LH}_{2}$ with the cooling system. One would also want to utilize the whole temperature span of the $\mathrm{LH}_{2}$ before the $\mathrm{H}_{2}$ is utilized in fuel cells, which makes the case for different temperature zones, as depicted in Figure 3. However, it adds challenges to the electrical interconnections, in which heat leakage will inevitably occur. The connectors should be strategically designed to limit these parasitic effects and to make the system easy to inspect. 


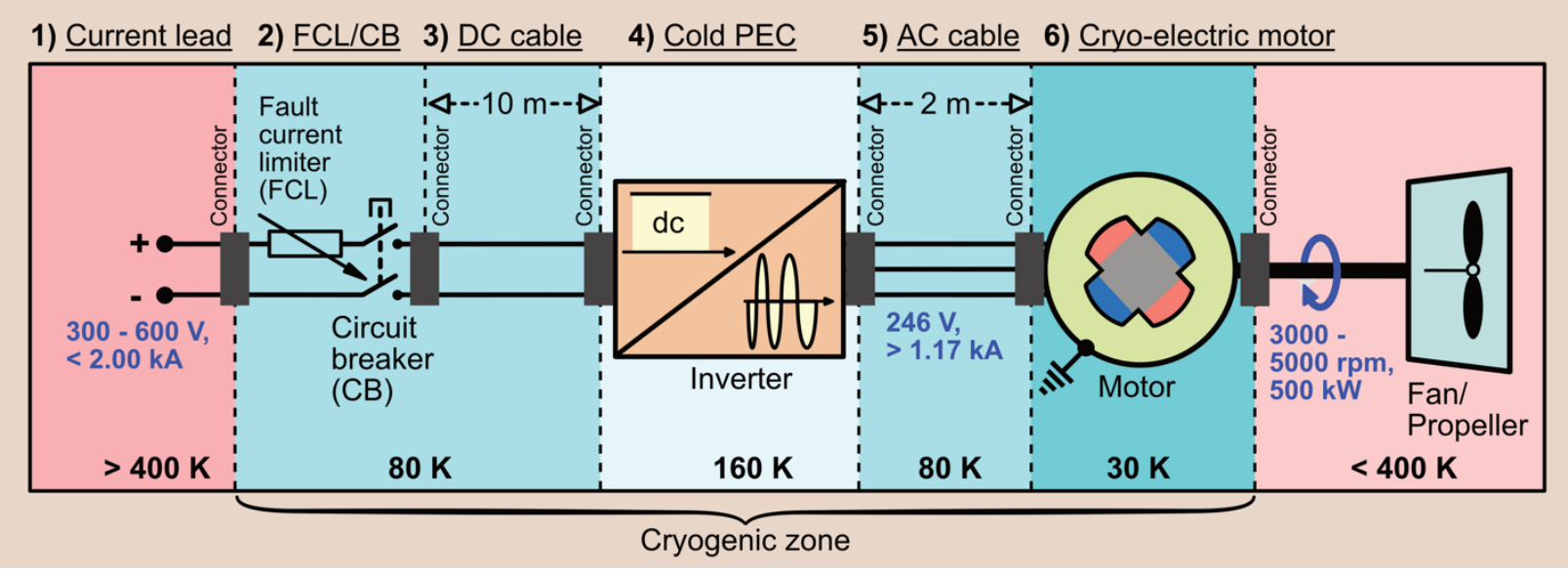

Figure 3 Cryogenic zone classification of ASCEND's 0.5-MW demonstrator including connectors.

Table 1 Airbus ASCEND project's figure-of-merits for the 0.5-MW demonstrator (Courtesy of Airbus UpNext).

\begin{tabular}{|c|c|c|c|c|c|c|}
\hline Component & Mass & Power density & Power in & Heat loss & Power out & Efficiency \\
\hline 1) Current lead & $10 \mathrm{~kg}$ & $50.8 \mathrm{~kW} / \mathrm{kg}$ & $508.6 \mathrm{~kW}$ & $0.2 \mathrm{~kW}$ & $508.4 \mathrm{~kW}$ & $>99.9 \%$ \\
\hline 2) Fault current limiter + circuit breaker & $10 \mathrm{~kg}$ & $50.7 \mathrm{~kW} / \mathrm{kg}$ & $508.4 \mathrm{~kW}$ & $0.2 \mathrm{~kW}$ & $508.2 \mathrm{~kW}$ & $>99.9 \%$ \\
\hline 3) DC cable (10 meter) + connectors & $25 \mathrm{~kg}$ & $20.3 \mathrm{~kW} / \mathrm{kg}$ & $508.2 \mathrm{~kW}$ & $0.1 \mathrm{~kW}$ & $508.1 \mathrm{~kW}$ & $>99.9 \%$ \\
\hline 4) CPE + filters & $35 \mathrm{~kg}$ & $14.3 \mathrm{~kW} / \mathrm{kg}$ & $508.1 \mathrm{~kW}$ & $6.0 \mathrm{~kW}$ & $502.1 \mathrm{~kW}$ & $98.8 \%$ \\
\hline 5) AC cable (2 meter) + connectors & $11 \mathrm{~kg}$ & $45.6 \mathrm{~kW} / \mathrm{kg}$ & $502.1 \mathrm{~kW}$ & $0.1 \mathrm{~kW}$ & $502.0 \mathrm{~kW}$ & $>99.9 \%$ \\
\hline 6) Direct-drive SCM & $40 \mathrm{~kg}$ & $12.5 \mathrm{~kW} / \mathrm{kg}$ & $502.0 \mathrm{~kW}$ & $2.0 \mathrm{~kW}$ & $500.0 \mathrm{~kW}$ & $99.6 \%$ \\
\hline Overall system & $131 \mathrm{~kg}$ & $3.8 \mathrm{~kW} / \mathrm{kg}$ & 508.6 kW & $8.6 \mathrm{~kW}$ & $500.0 \mathrm{~kW}$ & $98.3 \%$ \\
\hline
\end{tabular}

The overall power density of the drivetrain targeted in Table 1 can be verified with the following calculation

$$
p_{\text {tot }} \approx \frac{1}{\frac{1}{p_{1}}+\frac{1}{p_{2}}+\frac{1}{p_{3}}+\frac{1}{p_{4}}+\frac{1}{p_{5}}+\frac{1}{p_{6}}}
$$

where, $p_{1}, p_{2}$, etc., are the power density of each electrical component and $p_{\text {tot }}$ is the power density of the overall system. It can be clearly seen from Table 1 that the overall PTW is around 70 percent lower than the power density of SCMs. Moreover, the table indicates that the SCM has the lowest PTW, indicating that it is the most important component to improve further. 


\section{A Direct Hydrogen-Cooled Superconducting Propulsion System}

To move beyond the projects of ASUMED and ASCEND, further system-level improvements are needed, which are not merely focusing on the drivetrain segment of the system. These steps are described in the conceptual system outlined in Figure 4.

The available cooling capability of $\mathrm{LH}_{2}$ when raising the temperature from $20 \mathrm{~K}$ to $300 \mathrm{~K}$ is about 2.8 percent of the energy stored in the fuel (i.e., higher heating value - HHV). If the fuel cell is operated at an efficiency of about 60 percent, the amount of cryo-cooling and cooling energy combined is roughly 4.6 percent of the propulsion power at the electrical side. Moreover, considering that the overall inefficiency of the electrical system could be significantly less than this potential cooling energy, the feasibility of a synergy is inevitable. The less valuable cooling abilities at higher temperatures, but still below $60^{\circ} \mathrm{C}$, could be used for cooling the fuel cell, as indicated in the thermal circuit of Figure 4.

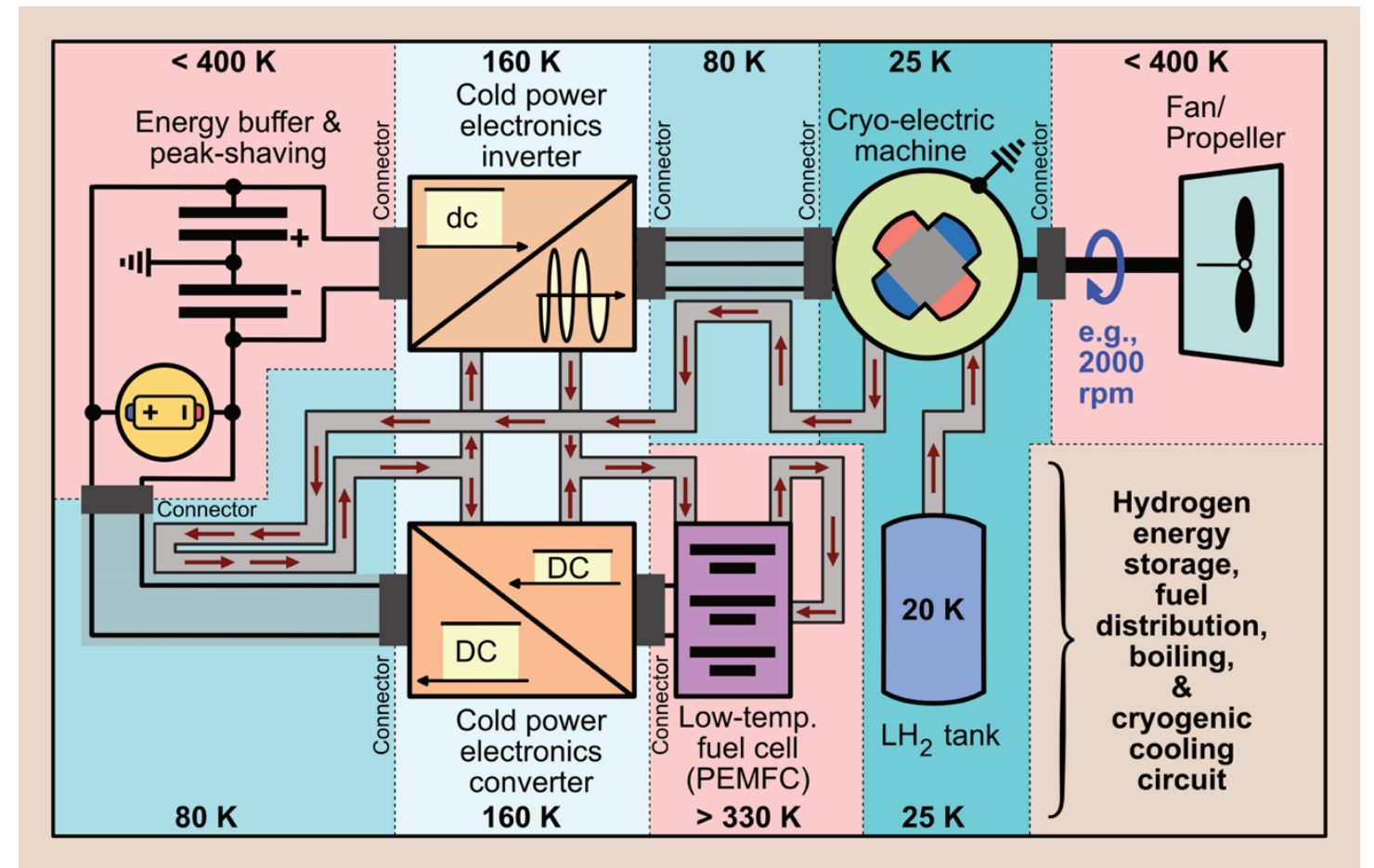

Figure 4 Sketch of a proposed architecture with cryogenic zone arrangement of a direct hydrogen-cooled propulsion system including heat exchange circuit.

\section{System-Level Mass and Inefficiency Savings}

To provide an estimation of the potential savings in the SCM, taking advantage of the system synergies proposed in Figure 4, the overall efficiency and power density of SCMs, including the effect of the cryocooler, must be accurately considered. The electrical power consumed by a cryocooler $\left(P_{\text {cryo }}\right)$ depends on the cryocooler efficiency $\left(\eta_{\text {cryo }}\right)$, the ambient temperature $\left(T_{\text {amb }}\right)$, the cryogenic temperature $\left(T_{\text {cryo }}\right)$, and the SCM's AC losses (Ploss,AC) as follows. 


$$
P_{\text {cryo }}=\frac{1}{\eta_{\text {cryo }}} \cdot \underbrace{\frac{T_{\text {amb }}-T_{\text {cryo }}}{T_{\text {cryo }}}}_{1 / \text { COP }} \cdot P_{\text {loss }, A C}
$$

Taking the additional power needs $\left(P_{\text {cryo }}\right)$ and the overall SCM losses ( $\left.P_{\text {loss,tot }}\right)$ into account, with $P_{\text {scm }}$ as the mechanical power of the SCM, the overall efficiency $\left(\eta_{\text {tot }}\right)$ is reduced, yielding:

$$
\eta_{\text {tot }}=\frac{P_{\text {scm }}}{P_{\text {scm }}+P_{\text {loss }, \text { tot }}+P_{\text {cryo }}}
$$

What is implied in this overall efficiency is not only the losses in the SCM itself but also the additional electrical power needed for cryocooling (i.e., $\mathrm{P}_{\text {cryo }}$ ) in the fully electrified aircraft, where extra fuel cell stack-mass would be required. Thus, eliminating $P_{\text {cryo }}$ makes the potential savings even better.

Table 2 Overall system considerations of a direct-drive 1.0-MW SCM comparing the performance with cryocooler against

\begin{tabular}{|c|c|c|c|}
\hline Parameter & Symbol & w/ cryocooler & w/ direct hydrogen cooling \\
\hline SCM efficiency & $\eta_{\text {mach }}$ & $99.7 \%$ & $99.7 \%$ \\
\hline SCM power density & $\mathrm{P}_{\mathrm{scm}} / \mathrm{m}_{\mathrm{mach}}$ & $12.5 \mathrm{~kW} / \mathrm{kg}-25.0 \mathrm{~kW} / \mathrm{kg}$ & $12.5 \mathrm{~kW} / \mathrm{kg}-25.0 \mathrm{~kW} / \mathrm{kg}$ \\
\hline SCM total heat losses & $P_{\text {loss,tot }}$ & $3.0 \mathrm{~kW}$ & $3.0 \mathrm{~kW}$ \\
\hline SCM AC losses & $P_{\text {loss }, A C}$ & $2.0 \mathrm{~kW}$ & $2.0 \mathrm{~kW}$ \\
\hline Cryocooler efficiency [25] & $\eta_{\text {cryo }}$ & $15 \%-30 \%$ & $\sim 100 \%$ \\
\hline Cryocooler mass per power loss removal [25] & $\mathrm{m}_{\text {cryo }} / \mathrm{P}_{\text {cryo }}$ & $3 \mathrm{~kg} / \mathrm{kW}$ & $\sim 0 \mathrm{~kg} / \mathrm{kW}$ \\
\hline Cryocooler mass per propulsion power & $m_{\text {cryo }} / P_{\text {scm }}$ & $0.22 \mathrm{~kg} / \mathrm{kW}-0.44 \mathrm{~kg} / \mathrm{kW}$ & $\sim 0 \mathrm{~kg} / \mathrm{kW}$ \\
\hline Cryocooler power & $P_{\text {cryo }}$ & $73.33 \mathrm{~kW}-146.67 \mathrm{~kW}$ & $\sim 0 \mathrm{~kW}$ \\
\hline Cryocooler mass & $\mathrm{m}_{\text {cryo }}$ & $220 \mathrm{~kg}-440 \mathrm{~kg}$ & $\sim 0 \mathrm{~kg}$ \\
\hline SCM mass & $\mathrm{m}_{\mathrm{scm}}$ & $40 \mathrm{~kg}-80 \mathrm{~kg}$ & $40 \mathrm{~kg}-80 \mathrm{~kg}$ \\
\hline Total mass of SCM + cryocooler & $m_{\text {tot }}$ & $260 \mathrm{~kg}-520 \mathrm{~kg}$ & $40 \mathrm{~kg}-80 \mathrm{~kg}$ \\
\hline Cryocooler mass contribution & $\mathrm{m}_{\text {cryo }} / \mathrm{m}_{\text {tot }}$ & $73.3 \%-91.7 \%$ & $\sim 0 \%$ \\
\hline Overall efficiency & $\eta_{\text {tot }}$ & $87.0 \%-92.9 \%$ & $\sim 99.7 \%$ \\
\hline Overall power density & $\mathbf{P}_{\mathrm{scm}} / \mathbf{m}_{\mathrm{tot}}$ & $1.92 \mathrm{~kW} / \mathrm{kg}-3.85 \mathrm{~kW} / \mathrm{kg}$ & $12.5 \mathrm{~kW} / \mathrm{kg}-25.0 \mathrm{~kW} / \mathrm{kg}$ \\
\hline
\end{tabular}
hydrogen cooling. Assumptions include $25 \mathrm{~K}$ cryogenic temperature $\left(T_{\text {cryo }}\right)$ and $300 \mathrm{~K}$ ambient temperature $\left(T_{\text {amb }}\right)$ at sea level. 
Table 2 outlines the calculation of the overall power density and efficiency for a 1.0-MW direct-drive SCM for regional flight, when the mass and power consumption of the cryocooler is also considered and compared against the concept of direct hydrogen cooling. It highlights the fact that the overall efficiency is between 6.8 and 12.7 percent lower than the efficiency of the SCM (i.e., $99.7 \%$ ), which is significant considering the additional energy needed onboard the aircraft to compensate for the inefficiency.

In addition, the power density, including the cryocooler, is lower than $3.85 \mathrm{~kW} / \mathrm{kg}$, which is comparable to the most power-dense conventional non-superconducting machines, even though the power density of SCM itself is considered to be higher than $12.5 \mathrm{~kW} / \mathrm{kg}$. The cryocooler dramatically reduces the PTW ratio of cryocooled SCMs by at least 69.2 percent. Earlier studies [26, 27] report that the mass of the cryocoolers can constitute as much as 70 percent of the total mass of the electric propulsion system.

From a holistic perspective, the SCM solution with cryocooler is rendered unfeasible due to its low efficiency and power density. Therefore, the only way to utilize the superior performance of the SCM is through other approaches such as direct hydrogen cooling, as proposed in this paper.

\section{Conclusions}

This article has proposed a new conceptual framework for the opportunities and developmental needs for the next-generation cryo-electric propulsion systems in zero-emission hydrogen-powered aviation. Recent projects and initiatives to move toward these objectives have been presented. We showcase the importance of enhancing the SCM when improving the power density of the drivetrain segment since it is the most limiting component in terms of mass and space occupation. Moreover, we emphasize major improvements found in using onboard cryogenic fuels onboard as a cooling medium, enabling an important synergy. Finally, our analysis shows that there is an extraordinary potential for massive weight and inefficiency savings for superconducting propulsion systems at the multi-megawatt level.

\section{Acknowledgements}

The authors gratefully acknowledge the support of SINTEF Energy Research, especially Niklas Magnusson, who provided important inputs to the manuscript from the field of superconductivity. In addition, thanks to Ida Hjorth for helping out with her expertise in gas technology and chemical engineering.

\section{Biographies}

Jonas Kristiansen Nøland and Runar Mellerud are with the Department of Electric Power Engineering at the Norwegian University of Science and Technology (NTNU), Trondheim, 7491, Norway.

Christian Hartmann is with the Institute for Energy Technology (IFE), Halden, 1777, Norway, but also with the Norwegian University of Science and Technology (NTNU). 


\section{References}

[1] "Hydrogen-powered aviation: A fact-based study of hydrogen technology, economics, and climate impact by 2050," Fuel Cells \& Hydrogen Joint Undertaking, Brussels, Belgium, May 2020 [Online], URL: https://www.fch.europa.eu/sites/default/files/FCH Docs/20200720 Hydrogen Powered Aviation report FINAL web.pdf

[2] J.K Nøland, "Hydrogen Electric Airplanes: A disruptive technological path to clean up the aviation sector", IEEE Electrification Magazine, vol. 9, no. 1, pp. 1-11, 2021, URL: https://ieeexplore.ieee.org/document/9371235

[3] K. Verfondern, et. al., "Handbook of Hydrogen Safety" (Chapter on $\mathrm{LH}_{2}$ Safety, pp. 18), PRESLHY, Fuels Cells and Hydrogen (FCH) Joint Undertaking, 2021, URL: https://hysafe.info/wp-content/uploads/sites/3/2021/04/D39_2021-01PRESLHY_ChapterLH2-v3.pdf

[4] H. Karmaker, et. al., "High power density superconducting rotating machines - Development status and technology roadmap," Superconductor Science and Technology, vol. 30, no. 12, 2017, URL: https://iopscience.iop.org/article/10.1088/1361-6668/aa833e/meta

[5] J. Han, et. al., "Influence of Electric Shield Materials on Temperature Distribution in the End Region of a Large WaterHydrogen-Hydrogen-Cooled Turbogenerator," IEEE Transactions on Industrial Electronics, vol. 67, no. 5, May 2020, URL: https://ieeexplore.ieee.org/document/8736046

[6] L. Weili, et. al., "Calculation of Ventilation Cooling, Three-Dimensional Electromagnetic Fields, and Temperature Fields of the End Region in a Large Water-Hydrogen-Hydrogen-Cooled Turbogenerator," IEEE Transactions on Industrial Electronics, vol. 60, no. 8, Aug. 2013, URL: https://ieeexplore.ieee.org/document/6211416

[7] M. Filipenko, et. al., "Concept design of a high power superconducting generator for future hybrid-electric aircraft," Superconductor Science and Technology, vol. 33, no. 5, March 2020, URL: https://iopscience.iop.org/article/10.1088/1361$6668 / a b 695 a$

[8] B. Lukasik, et. al., "Turboelectric distributed propulsion system as a future replacement for turbofan engines," Proc. ASME Turbo Expo, no. GT2017-63834, V001T01A017, Aug. 2017, URL: https://asmedigitalcollection.asme.org/GT/proceedings/GT2017/50770/V001T01A017/291323

[9] Y. Terao, et. al., "Lightweight Design of Fully Superconducting Motors for Electrical Aircraft Propulsion Systems," IEEE Transactions on Applied Superconductivity, vol. 29, no. 5, Aug. 2019, URL: https://ieeexplore.ieee.org/document/8654678

[10] R. Sugouchi, et. al., "Conceptual Design and Electromagnetic Analysis of 2 MW Fully Superconducting Synchronous Motors With Superconducting Magnetic Shields for Turbo-Electric Propulsion System," IEEE Transactions on Applied Superconductivity, vol. 30, no. 4, June 2020, URL: https://ieeexplore.iee.org/document/9001263

[11] "ASUMED: System topology report," H2020 project delivery report, grant no. 723119, Oct. 2017, URL: http://asumed.oswald.de/images/pdf/ASuMED_D1.2_system-topology-report.pdf

[12] F. Grilli, et. al., "Superconducting motors for aircraft propulsion: the Advanced Superconducting Motor Experimental Demonstrator project," Journal of Physics: Conference Series, no. 1590, 2020, URL: https://iopscience.iop.org/article/10.1088/1742-6596/1590/1/012051/pdf

[13] M. Zhang, "A new world record for a superconducting trapped field magnet," Superconductor Science and Technology, vol. 32, no. 7, June 2019, URL: https://iopscience.iop.org/article/10.1088/1361-6668/ab17e6

[14] T. Qu, et. al., "Development and testing of a $2.5 \mathrm{~kW}$ synchronous generator with a high temperature superconducting stator and permanent magnet rotor," Superconductor Science and Technology, vol. 27, no. 7, March 2014, URL: https://iopscience.iop.org/article/10.1088/0953-2048/27/4/044026

[15] C. D. Manolopoulos, et. al., "Stator Design and Performance of Superconducting Motors for Aerospace Electric Propulsion Systems," IEEE Transactions on Applied Superconductivity, vol. 28, no. 4, June 2018, URL:

https://ieeexplore.ieee.org/document/8310968 
[16] M. Corduan, et. al., "Topology Comparison of Superconducting AC Machines for Hybrid Electric Aircraft," IEEE Transactions on Applied Superconductivity, vol. 30, no. 2, March 2020, URL: https://ieeexplore.ieee.org/document/8947911

[17] P. Masson, et. al., "Safety Torque Generation in HTS Propulsion Motor for General Aviation Aircraft," IEEE Transactions on Applied Superconductivity, vol. 17, no. 2, June 2007, URL: https://ieeexplore.ieee.org/document/4277589

[18] K. Rajashekara, B. Akin, "Cryogenic Power Conversion Systems: The next step in the evolution of power electronics technology," IEEE Electrification Magazine, vol. 1, no. 2, Dec. 2013, URL: https://ieeexplore.ieee.org/document/6749061

[19] A. Elwakeel, et. al., "Study of Power Devices for Use in Phase-Leg at Cryogenic Temperature," IEEE Transactions on Applied Superconductivity, vol. 31, no. 5, Aug. 2021, URL: https://ieeexplore.iee.org/document/6749061

[20] H. Gui, et. al., "Review of Power Electronics Components at Cryogenic Temperatures," IEEE Transactions on Power Electronics, vol. 35, no. 5, May 2020, URL: https://ieeexplore.ieee.org/document/8854889

[21] H. Gui, et. al., "Development of High-Power High Switching Frequency Cryogenically Cooled Inverter for Aircraft Applications," IEEE Transactions on Power Electronics, vol. 35, no. 6, June 2020, URL:

https://ieeexplore.ieee.org/document/8883075

[22] L. Nela, et. al., "Performance of GaN Power Devices for Cryogenic Applications Down to 4.2 K," IEEE Transactions on Power Electronics, vol. 36, no. 7, July 2021, URL: https://ieeexplore.ieee.org/document/9309188

[23] R. Chen, F. F. Wang, "SiC and GaN Devices With Cryogenic Cooling," IEEE Open Journal of Power Electronics, vol. 2, pp. 315326, April 2021, URL: https://ieeexplore.ieee.org/document/9411696

[24] C. B. Barth, et. al., "Design, Operation, and Loss Characterization of a 1-kW GaN-Based Three-Level Converter at Cryogenic Temperatures," IEEE Transactions on Power Electronics, vol. 35, no. 11, Nov. 2020, URL:

https://ieeexplore.ieee.org/document/9075366

[25] J. L. Felder, et. al., "Turboelectric Distributed Propulsion in a Hybrid Wing Body Aircraft," NASA Glenn Research Center, 2011, URL: https://ntrs.nasa.gov/api/citations/20120000856/downloads/20120000856.pdf?attachment=true

[26] C. E. Jones, et. al., "Comparison of Candidate Architectures for Future Distributed Propulsion Aircraft," IEEE Transactions on Applied Superconductivity, vol. 26, no. 6, Sept. 2016, URL: https://ieeexplore.ieee.org/document/7407568

[27] F. Berg, et. al., "HTS Electrical System for a Distributed Propulsion Aircraft," IEEE Transactions on Applied Superconductivity, vol. 25, no. 3, June 2015, URL: https://ieeexplore.ieee.org/document/7024922 